\title{
Editorial
}

\section{Conference of the International Clinical Hyperthermia Society 2012}

\author{
Gianfranco Baronzio, ${ }^{1}$ Michael Jackson, ${ }^{2}$ Dooyun Lee, ${ }^{3}$ and András Szász ${ }^{4}$ \\ ${ }^{1}$ Centro Medico Demetra, Center for Clinical Hyperthermia and Immunity, 05100 Terni, Italy \\ ${ }^{2}$ Prince of Wales Hospital, Sydney, NSW 2031, Australia \\ ${ }^{3}$ Gangnam Severance Hospital, Yonsei University, Seoul 135-720, Republic of Korea \\ ${ }^{4}$ Biotechnics Department, St. Istvan University, Godollo 2100, Hungary \\ Correspondence should be addressed to András Szász; szasz.andras@gek.szie.hu
}

Received 4 November 2013; Accepted 4 November 2013

Copyright (C) 2013 Gianfranco Baronzio et al. This is an open access article distributed under the Creative Commons Attribution License, which permits unrestricted use, distribution, and reproduction in any medium, provided the original work is properly cited.

Cancer has been a permanent fear for human kind since the ancient era. Since the ancient times, we have continuously fought against malignant disease, and this has been one of the greatest challenges in medical science for centuries. In 1971, "war" was declared in the United States against cancer. Oncology has now become one of the most interdisciplinary research fields and includes biology, biophysics, biochemistry, genetics, environmental sciences, epidemiology, immunology, microbiology, pathology, physiology, pharmacology, psychology, and virology. Moreover, a wide range of diagnostic and treatment methods are available to identify and destroy malignant tissue. Enormous economic and human resources are involved in this field, but we have only been partially successful. According to epidemiological data, the complete solution is still much awaited.

The 31st Annual Conference of the International Clinical Hyperthermia Society (ICHS) was a part of the "war." The topic is not new, hyperthermia is an ancient treatment, which is in fact the very first used in oncology. After a long dormant period, hyperthermia has been renewed, with the delivery of electromagnetic energy giving new perspectives. Definitely, hyperthermia promises a lot; a method with low toxicity and rare complications is a long-time dream and at the same time is one of the great needs of oncology practice. The combination of biochemical approaches with biophysical methods could be a perfect combination giving a synergistic destruction of malignancy. Oncological hyperthermia is an ideal combination therapy; it provides synergies with most of the conventional treatment modalities, boosts their efficacy, and helps to resensitize cells to previously ineffective treatments.

There are a great number of books devoted to the efficacy and the power of hyperthermia in oncology [1-20]. However, despite its long history, the state of oncological hyperthermia today is similar to that of the therapies in their infancy. Like many early-stage therapies, it lacks adequate treatment experience and long-term, comprehensive statistics that can help us optimize its use for all indications. The promise of hyperthermia applications in oncology is high, and it has shown numerous positive impacts together with all the conventional and emerging new oncotherapies. The picture is very positive and it looks plausible that the method is at the center of interest among the specialists in oncology and related medical fields. But in fact, it is not! Doubts shadow the bright picture. Despite the large number of excellent published clinical results, the challenge of hyperthermia in oncology is understandable from the perspective of a few thousand years. Medicine faces unsolved problems in hyperthermia, mainly, because of its controversial results obtained from the very beginning. While the mechanisms of hyperthermia are unexplained, its optimal control for efficacy and for safety remains unresolved as well.

The challenges look technically simple:

(i) deliver the heat to deep targets in the body; 
(ii) have adequate and measurable feedback during treatment;

(iii) select the malignant cells to treat;

(iv) apply effective cell killing and effectively control it;

(v) reduce the risk, increase the safety of the patient, reduce the possible side effects;

(vi) increase the safety of the treating personnel and the environment;

(vii) make the procedure relatively simple with acceptable complications;

(viii) have an attractive cost/benefit ratio.

However, these are only the superficial problems. The challenge is complex as physiological regulation has powerful feedback mechanisms trying to reestablish homeostatic control and thus reducing local hyperthermia by spreading the temperature from the focus. This complexity causes many technically challenging points.

The aim and expectation of the application of hyperthermia is the same as the overall accepted paradigm in oncology: kill the tumor cells.

Destroying the tumor, or at least diminishing the number of the malignant cells, requires the ability to target them selectively without causing considerable damage to healthy tissue.

Probably, hyperthermia is one of the subjects which has had most questions in the published literature. Numerous definite questions were formulated at the conference, for example:

(i) is the community radiation oncologist ready for clinical hyperthermia [21]?

(ii) Is there a future for hyperthermia in cancer treatment [22]?

(iii) Is heating the patient a promising approach [23]?

(iv) Has the time of hyperthermia come [24]?

(v) What is against the acceptance of hyperthermia [25]?

(vi) What is the progress in hyperthermia [26]?

(vii) Is the Prostate cancer hot, but is it hot enough [27]?

(viii) What happened to hyperthermia and what is its current status in cancer treatment [28]?

(ix) Where there is smoke, is there fire [29]?

(x) Should interstitial thermometry be used for deep hyperthermia [30]?

(xi) If we cannot define the quality, can we assure it [31]?

Questions pile up, but satisfactorily answers were still missing. The real challenges are of course the sometimes controversial results, raising many further doubts and questions. A further question obviously arises: what do we now know? The aim of the present ICHS conference was to address this question and discuss possible routes for further progress. Papers deal with these problems, summarizing where we are. The presented material summarizes results from a large field of oncological hyperthermia, showing the update results of classical focused electromagnetic heating, focused mechanical energy delivery, the electric field, promoted selection of the cells, and the immune actions of the synergy of heat with an electric field. Theoretical considerations of hyperthermia effects are well combined with different, in vitro, in vivo, preclinical and clinical applications.

Various laboratory results, together with the preclinical achievements, are presented showing the current biomedical basis of modern hyperthermia and successfully solving the challenges of focusing, selecting and controlling of the hyperthermia process.

The clinical results show consistent efficacy in the treatment of advanced malignancies, even in refractory, relapsed, and heavily pretreated cases. The monotherapy applications in cases when no other treatment could be applied successfully show the great potential of hyperthermia among the various modalities of oncotherapies. Oncological aspects of HIV were prepared for clinical research. The well-documented synergy with integrated medical approaches like the traditional Chinese medicine (TCM) opens new perspectives in hyperthermia application together with new efforts to treat nononcological diseases which respond poorly to the other presently available method.

This proceeding of the ICHS conference is an invitation to share the challenge of the new method, to share the excitement of applying an effective new treatment, and to share the enjoyment of the results.

Gianfranco Baronzio Michael Jackson

Dooyun Lee

András Szász

\section{References}

[1] C. Streffer, D. Van Beuningen, F. Dietzerl et al., Cancer Therapy by Hyperthermia and Radiation, Urban and Schwarzenberg, Baltimore, Md, USA, 1978.

[2] N. B. Hornback, Hyperthermia and Cancer: Human Clinical Trial Experience, CRC Press, Boca Raton, Fla, USA, 1984.

[3] M. Gautherie and E. Albert, Eds., Biomedical Thermology, Alan R. Liss, New York, NY, USA, 1982.

[4] L. J. Anghileri and J. Robert, Hyperthermia in Cancer Treatment, vol. 1-3, CRC Press, Boca Raton, Fla, USA, 1986.

[5] S. B. Field and C. Franconi, Eds., Physics and Technology of Hyperthermia, NATO ASI series, Martinus Nijhoff, Dordrecht, The Netherlands, 1987.

[6] M. Urano and E. Douple, Eds., Hyperthermia and Oncology, Vol. 1. Thermal Effects on Cells and Tissues, VSP BV, Utrecht, The Netherlands, 1989.

[7] M. Urano and E. Douple, Eds., Hyperthermia and Oncology, Vol. 2. Biology of Thermal Potentiation of Radiotherapy, VSP BV, Utrecht, The Netherlands, 1989.

[8] M. Gautherie, Ed., Methods of Hyperthermia Control, Springer, Berlin, Germany, 1990.

[9] M. Gautherie, Ed., Biological Basis of Oncological Thermotherapy, Springer, Berlin, Germany, 1990.

[10] M. Gautherie, Ed., Interstitial Endocavitary and Perfusional Hyperthermia, Springer, Berlin, Germany, 1990. 
[11] M. Urano and E. Douple, Eds., Hyperthermia and Oncology, Vol. 3. Interstitial Hyperthermia: Physics, Biology and Clinical Aspects, VSP BV, Utrecht, The Netherlands, 1992.

[12] M. H. Seegenschmiedt and R. Sauer, Interstitial and Intracavitary Thermoradiotherapy, Springer, Berlin, Germany, 1993.

[13] T. Matsuda, Ed., Cancer Treatment by Hyperthermia, Radiation and Drugs, Taylor \& Francis, London, UK, 1993.

[14] M. Urano and E. Douple, Eds., Hyperthermia and Oncology, Vol. 4. Chemopotentiation by Hyperthermia, VSP BV, Utrecht, The Netherlands, 1994.

[15] M. H. Seegenschmiedt, P. Fessenden, and C. C. Vernon, Eds., Thermoradiotherapy and Thermochemotherapy, Vol. 1. Biology, Physiology and Physics, Springer, Berlin, Germany, 1996.

[16] M. H. Seegenschmiedt, P. Fessenden, and C. C. Vernon, Eds., Thermo-Radiotherapy and Thermo-Chemiotherapy, Volume 2. Clinical Applications, Springer, Berlin, Germany, 1996.

[17] M. Kosaka, T. Sugahara, K. L. Schmidt et al., Eds., Thermotherapy for Neoplasia, Inflammation, and Pain, Springer, Tokyo, Japan, 2001.

[18] L. M. Ellis, S. A. Curley, and K. K. Tanabe, Radiofrequency Ablation of Cancer, Springer, New York, NY, USA, 2004.

[19] G. F. Baronzio and E. D. Hager, Eds., Hyperthermia in Cancer Treatment: A Primer, Springer, Landes Bioscience, 2006.

[20] A. Szasz, N. Szasz, and O. Szasz, Oncothermia-Principles and Practices, Springer, Dordrecht, The Netherlands, 2010.

[21] N. B. Hornbach, "Is the community radiation oncologist ready for clinical hyperthermia?" RadioGraphics, vol. 7, pp. 139-141, 1987.

[22] O. S. Nielsen, M. Horsman, and J. Overgaard, "A future for hyperthermia in cancer treatment?" European Journal of Cancer, vol. 37, no. 13, pp. 1587-1589, 2001.

[23] J. van der Zee, "Heating the patient: a promising approach?" Annals of Oncology, vol. 13, no. 8, pp. 1173-1184, 2002.

[24] W. R. Smythe and P. F. Mansfield, "Hyperthermia: has its time come?” Annals of Surgical Oncology, vol. 10, no. 3, pp. 210-212, 2003.

[25] A. Szasz, "What is against the acceptance of hyperthermia?" Die Naturheilkunde Forum-Medizine, vol. 83, pp. 3-7, 2006.

[26] J. R. Oleson, "Progress in hyperthermia?" International Journal of Radiation Oncology, Biology, Physics, vol. 20, pp. 1147-1164, 1991.

[27] J. R. Oleson, "Prostate cancer: hot, but hot enough?" International Journal of Radiation Oncology Biology Physics, vol. 26, no. 2, pp. 369-370, 1993.

[28] F. K. Storm, "What happened to hyperthermia and what is its current status in cancer treatment?" Journal of Surgical Oncology, vol. 53, no. 3, pp. 141-143, 1993.

[29] D. M. Brizel, "Where there's smoke, is there fire?" International Journal of Hyperthermia, vol. 14, no. 6, pp. 589-591, 1998.

[30] P. K. Sneed, M. W. Dewhirst, T. Samulski, J. Blivin, and L. R. Prosnitz, "Should interstitial thermometry be used for deep hyperthermia?" International Journal of Radiation Oncology Biology Physics, vol. 40, no. 5, pp. 1015-1017, 1998.

[31] J. R. Oleson, "If we can't define the quality, can we assure it?" International Journal of Radiation Oncology, Biology, Physics, vol. 16, p. 879, 1989. 

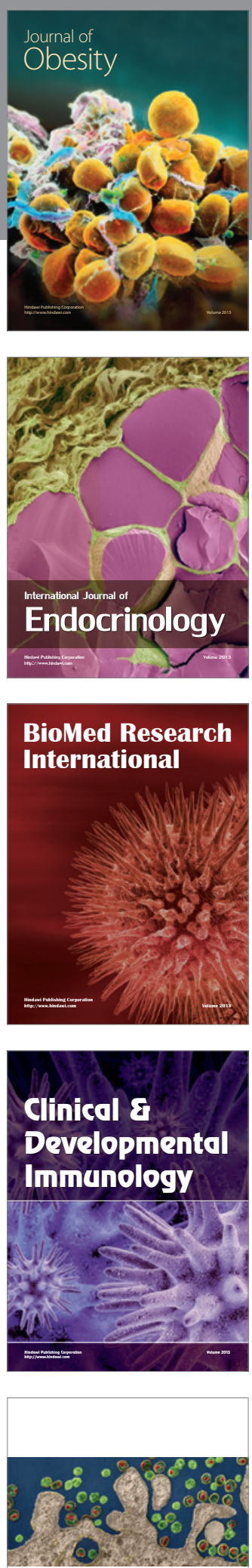

ISRN

AIDS
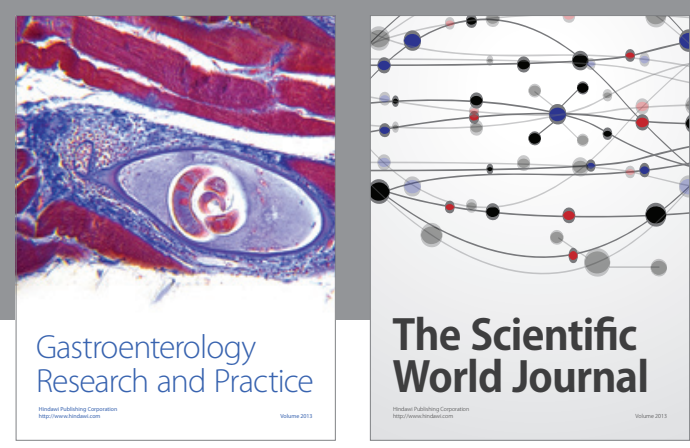

The Scientific World Journal
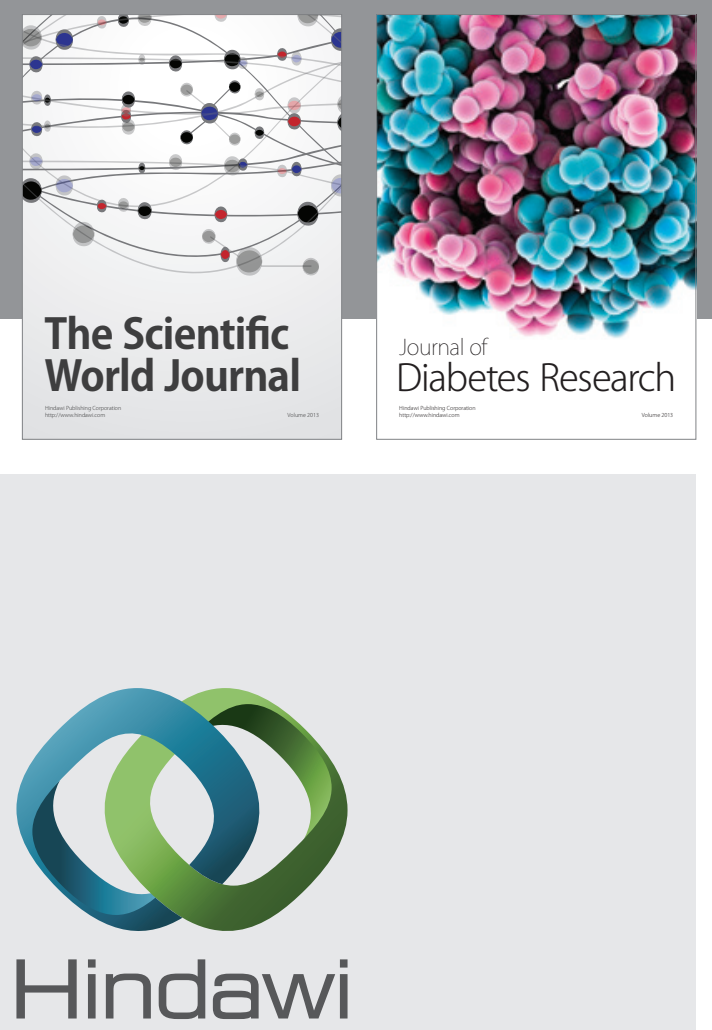

Submit your manuscripts at

http://www.hindawi.com
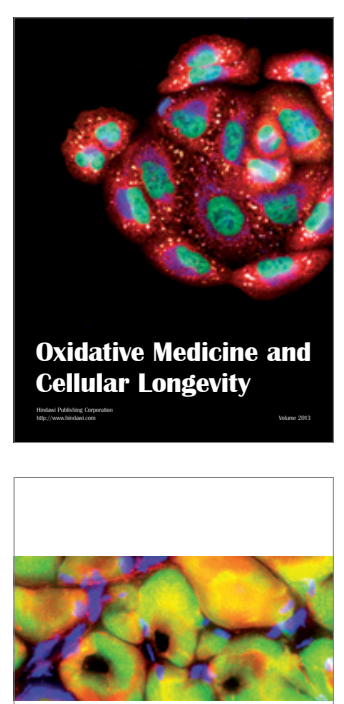

ISRN

Biomarkers
MEDIATORS

INFLAMMATION
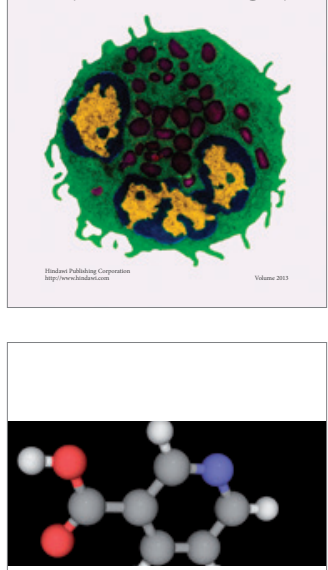

ISRN

Addiction
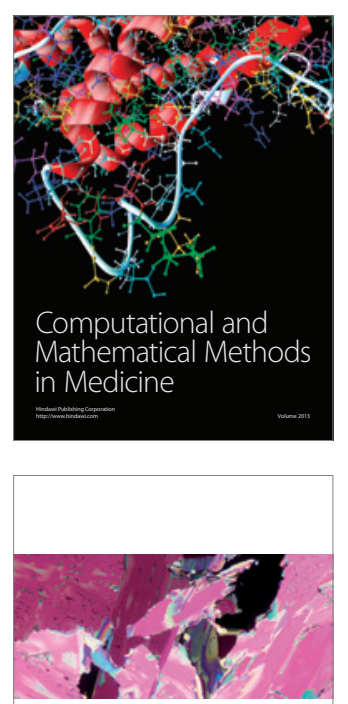

ISRN

Anesthesiology
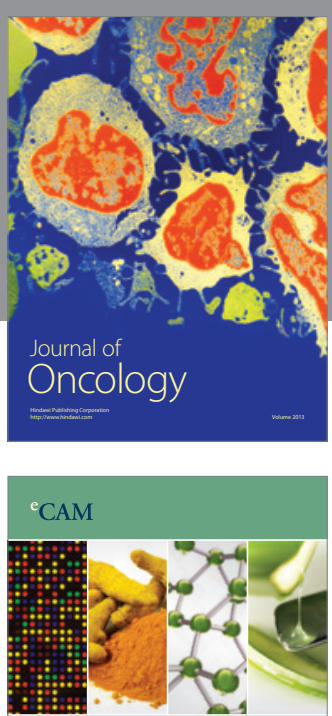

Evidence-Based

Complementary and

Alternative Medicine
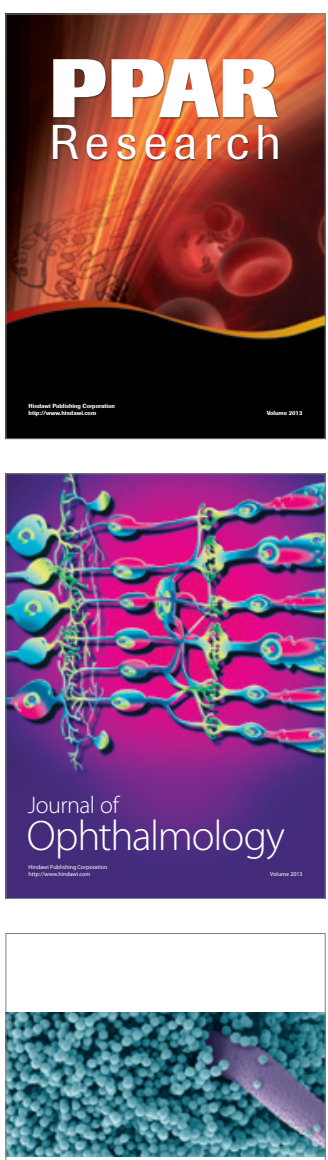

ISRN

Allergy 


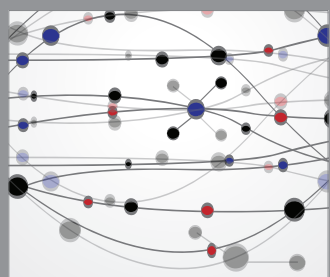

The Scientific World Journal
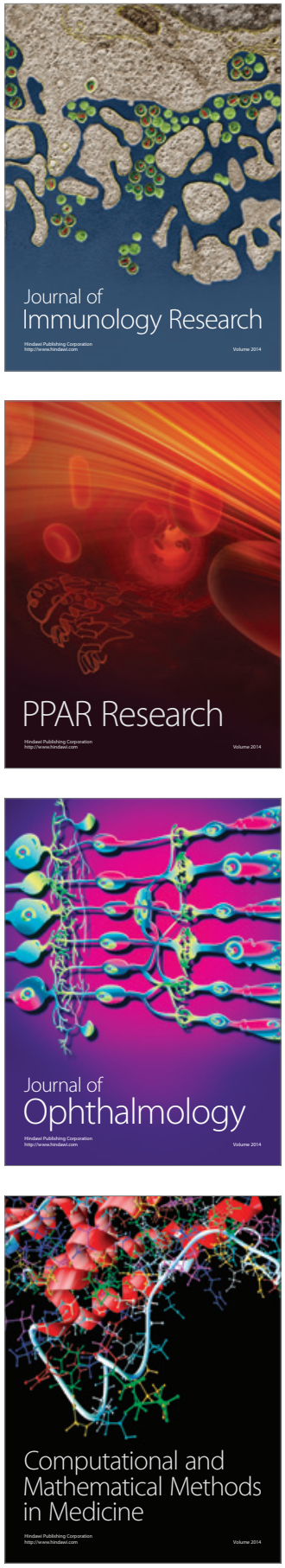

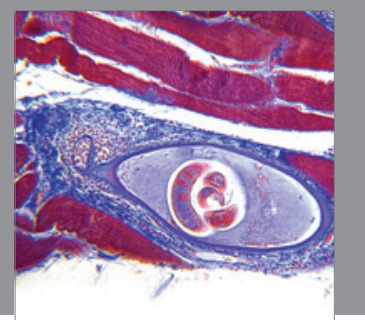

Gastroenterology

Research and Practice
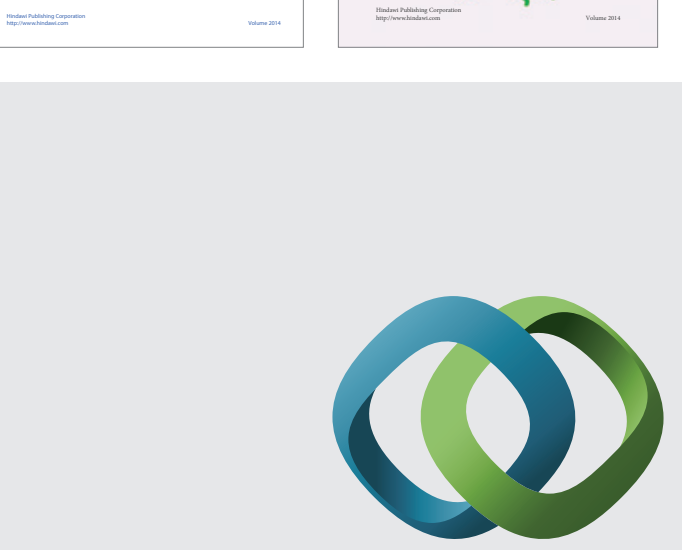

\section{Hindawi}

Submit your manuscripts at

http://www.hindawi.com
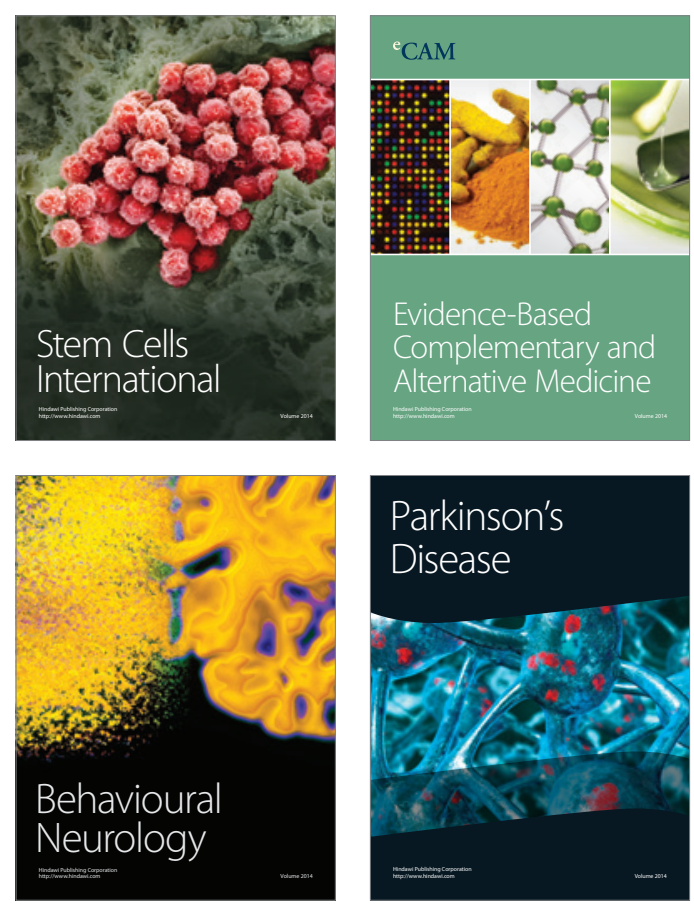

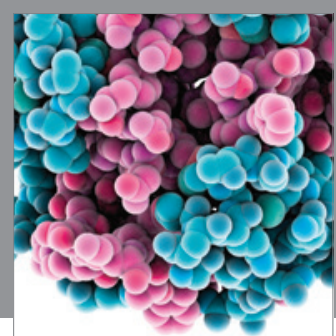

Journal of
Diabetes Research

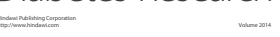

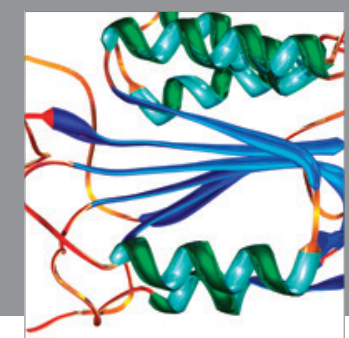

Disease Markers
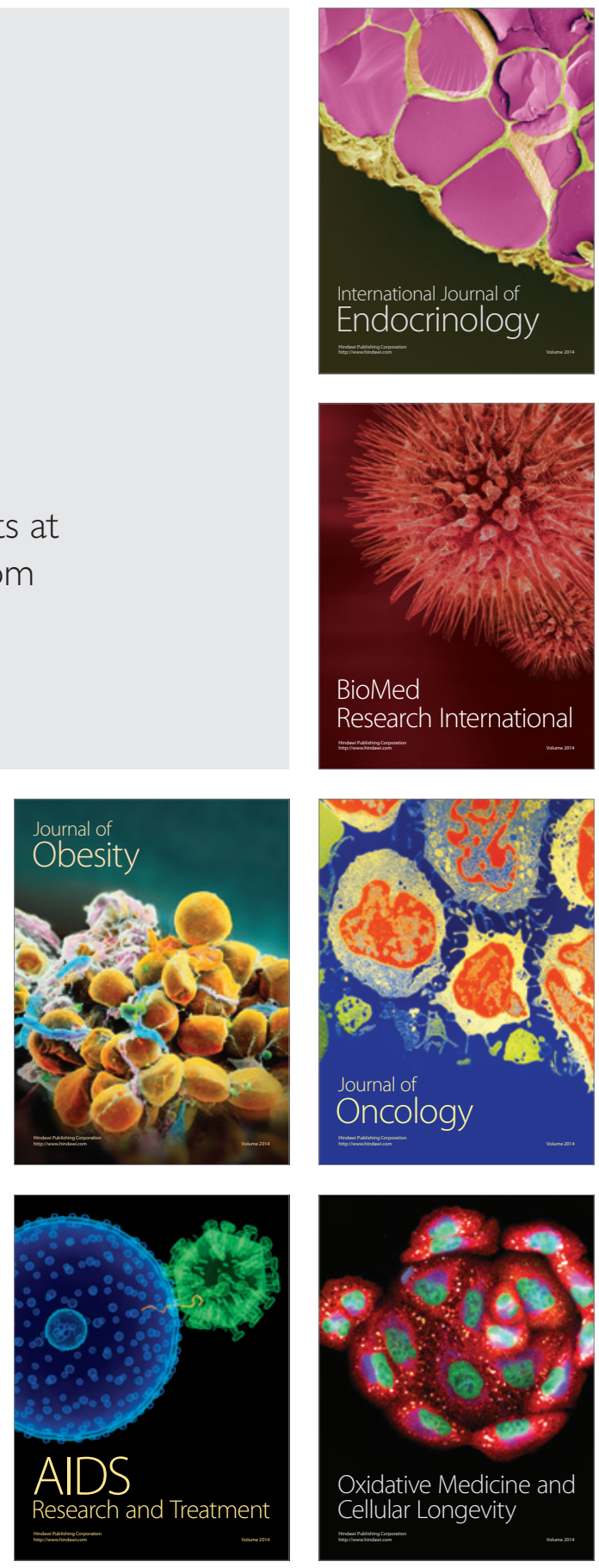